\title{
An Experimental and Numerical Study of a Supersonic Burner for CFD Model Development
}

\author{
G. Magnotti ${ }^{1}$ and A. D. Cutler ${ }^{2}$ \\ The George Washington University, Newport News, VA, 23602
}

\begin{abstract}
A laboratory scale supersonic burner has been developed for validation of computational fluid dynamics models. Detailed numerical simulations were performed for the flow inside the combustor, and coupled with finite element thermal analysis to obtain more accurate outflow conditions. A database of nozzle exit profiles for a wide range of conditions of interest was generated to be used as boundary conditions for simulation of the external jet, or for validation of non-intrusive measurement techniques. A set of experiments was performed to validate the numerical results. In particular, temperature measurements obtained by using an infrared camera show that the computed heat transfer was larger than the measured value. Relaminarization in the convergent part of the nozzle was found to be responsible for this discrepancy, and further numerical simulations sustained this conclusion.
\end{abstract}

\section{Nomenclature}

$d \quad=$ thickness

$h=$ convective heat transfer coefficient

$k=$ thermal conductivity

$K_{1}, K_{4}=$ acceleration parameter

$M \quad=$ Mach number

$M_{e} \quad=$ nozzle exit Mach number

$M_{f} \quad=$ simulated flight Mach number

$p \quad=$ pressure

$Q \quad=$ volumetric flow rate

$q \quad=$ heat flux

$\operatorname{Re}_{\theta} \quad=$ Reynolds number based on the momentum thickness

$T=$ temperature

$T_{0} \quad=$ stagnation temperature

$T_{a w} \quad=$ adiabatic wall temperature

$T_{w} \quad=$ wall temperature

$T K E=$ turbulent kinetic energy

$U \quad=$ axial velocity

$x \quad=$ axial distance

$y \quad=$ radial distance

$y^{+} \quad=$ dimensionless normal turbulence coordinate

$\theta \quad=$ momentum thickness

$\mu_{w} \quad=$ dynamic viscosity at the wall

$v \quad=$ kinematic viscosity

$\rho \quad=$ density

\section{Introduction}

Design and analysis of scramjet engines is complex, wind tunnel testing is costly and generally limited to low hypersonic Mach numbers or very short duration. Only a few, successful flight experiments have been

${ }^{1}$ Graduate Student, AIAA Student Member

${ }^{2}$ Professor, MAE Dep’t, 1 Old Oyster Point Road, Suite 200. Associate Fellow AIAA. 
accomplished to date. When tests are conducted, taking measurements is challenging because of the elevated speed and temperature typical of the hypersonic environment in which these engines operate. Because of these challenges, computational fluid dynamics (CFD) has played a key role in the design of hypersonic airbreathing engines. Most codes currently used to design scramjet engines solve the Reynolds average Navier-Stokes equations, employing models to describe turbulence and chemistry. These models need to be calibrated and validated in environment close to the one encountered in a scramjet engine before they can be used with confidence in a design process. For example, models employing constant turbulent Prandtl and Schmidt numbers are often inadequate to describe a supersonic flame. Unfortunately, not enough data are available to the modelers to develop and validate their codes, due to difficulties in taking measurements and lack of facilities adequate for validation experiments. In recent years, several efforts have been made at NASA Langley to improve measurement techniques and to design facilities adequate for validation purposes.

Non-intrusive measurement techniques are desirable in a hypersonic environment, because probes inserted in the flow would generate shock waves strongly affecting the flowfield, and would be subject to very large pressure and heat fluxes. At NASA Langley, dual-pump coherent anti-Stokes Raman spectroscopy (CARS), originally developed by Lucht ${ }^{1}$, has been used to measure temperature and species concentration $\left(\mathrm{O}_{2}, \mathrm{~N}_{2}, \mathrm{H}_{2}\right)$ in an $\mathrm{H}_{2}$ fueled supersonic combustor $^{2,3}$. Recently dual-pump CARS has been successfully coupled to interferometric Rayleigh scattering (IRS) to add velocity measurements to the capability of the system ${ }^{4,5}$. Simultaneous, single point measurements of all three variables would provide the CFD modelers with those quantities (means, variance, co-variances) necessary for calibration and validation purposes.

Facilities are also required that provide a flowfield that is representative of the environment encountered in scramjet engines, but that is also simple enough so that the CFD modelers can easily extract the information they need. The SCHOLAR experiment ${ }^{2,3}$, conducted at NASA Langley, was a supersonic combusting flow in a duct intended to be used as benchmark for the validation process. The geometry was simple, but the flowfield turned out to be much more complex and challenging than expected ${ }^{6}$, making it difficult for the modelers to extract useful information from the experimental data. Learning from the SCHOLAR experience a new facility was designed for validation studies.

An axisymmetric supersonic combusting coaxial jet facility was developed, which provided excellent optical access. The symmetry offered by the coaxial burner was critical in minimizing the numbers of measurement points required to map the flowfield ${ }^{7,8}$. The facility provides a central jet of hot "vitiated air" simulating the hot air entering the engine of a hypersonic vehicle flying at Mach numbers $\left(M_{f}\right)$ between 5 and 7 . The vitiated air is the product of combustion of $\mathrm{O}_{2}$-enriched air with $\mathrm{H}_{2}$ and has the enthalpy and the $\mathrm{O}_{2}$ mass fraction of the hot air but not the composition; therefore, it may not be able to reproduce the flame holding properties. Three different nozzles, with exit Mach number $\left(\mathrm{M}_{\mathrm{e}}\right)$ 1, 1.6 and 2, are used to provide flows with the effects of varying compressibility. $\mathrm{H}_{2}$ or hydrocarbon coaxial co-flow is available in order to generate a supersonic combusting free jet. Two different sizes of experimental hardware have been developed; the first with flow rates compatible with a combustion diagnostics laboratory, the second scaled up by a factor of 6.35 from the smaller device and mounted in the NASA Langley's Direct Connect Supersonic Combustion Test Facility. Previous publications extensively describe the large-scale burner, and some numerical and experimental results have already been published ${ }^{9,10}$.

The objective of this paper is to characterize the flow field in the laboratory scale device for a wide range of conditions, with particular attention given to the flow at the exit of the nozzle. Computational methods were employed involving both CFD of the flow field and finite element thermal analysis (FEM) of the structures. Experiments were conducted in order to validate the numerical results. A database of internal flowfield and nozzle temperatures was generated to provide boundary conditions for simulations of the combusting free jet, or as benchmark for measurements at the nozzle exit obtained with our CARS-IRS system or other non-intrusive techniques.

\section{Facility Description}

Figure 1 shows the burner and the nozzle sectioned along the symmetry plane and without bolts, tubes, spark plugs and other fittings. The facility consists of an injection system, a premixing chamber, a water-cooled burner, and a ceramic nozzle surrounded by a co-flow nozzle. 
The $\mathrm{H}_{2}$ injection system consists of a stainless steel tube with an external diameter of $1 / 8^{\text {th }}$ of an inch $(3.175 \mathrm{~mm})$ and a 0.084 inch $(2.133 \mathrm{~mm})$ internal diameter. The tube terminates with the external wall inclined at 30 degrees. The enriched air flows in the annular passage created by the water-cooled injector (internal diameter $4.76 \mathrm{~mm}$ ) and the $\mathrm{H}_{2}$ tube. The relative position of the $\mathrm{H}_{2}$ tube and the combustion chamber determines the length of the mixing chamber. This length is fixed to $40 \mathrm{~mm}$ in order to ensure adequate mixing before the gases enter the combustion chamber, based on previous experiments and preliminary CFD calculations. In previous tests, a fully premixed flow entering the combustion chamber was attempted, but the flame propagated back to the injection system during combustion ignition, resulting in an unsafe operating regime. The injector is water cooled, although in the normal operation regime, the heat fluxes on its surface are negligible. The premixing chamber terminates with a sudden expansion when the reactants reach the combustion chamber. A spark plug placed at the entrance of the combustion chamber ignites the partially premixed gases. The sudden expansion generates a large recirculation region, ensuring flameholding and stability of combustion in the burner. The combustion chamber consists of an exterior "jacket" and an interior "shell" between which water flows for cooling. The "shell" has an internal diameter of $25.4 \mathrm{~mm}$ and is $152 \mathrm{~mm}$ long. One of three interchangeable ceramic nozzles (one sonic, and two supersonic with $M_{e}=1.6$ and 2 respectively) is mounted at the exit of the combustion chamber. The nozzles have a $10 \mathrm{~mm}$ exit diameter. The nozzle contours were designed using the method of the characteristics, assuming a ratio of specific heat capacities equal to 1.3.

An "annulus" surrounds the nozzle, holding it in place, and with the exterior wall of the nozzle creates an annular, convergent "co-flow" nozzle. The co-flow gas is injected into a pre-chamber, which distributes the flow in the circumferential direction, and enters the co-flow nozzle through a narrow passage $(0.5 \mathrm{~mm}$ wide). This design produces a more uniform flow distribution at the co-flow nozzle exit, necessary to maintain the axisymmetric hypothesis, addressing an issue encountered with the previous design. The internal diameter of the co-flow nozzle is $8 \mathrm{~mm}$, the external $9 \mathrm{~mm}$. The co-flow and center jets are concentric and separated by the $3 \mathrm{~mm}$ wide, annular base region of the nozzle, orthogonal to the center jet. The "annulus" external walls are inclined at 60 degrees to improve the optical access.

The injector, the burner (shell and jacket) and the annulus are made of AISI 310 stainless steel. The three nozzles are made of Hexaloy grade SA silicon carbide. This ceramic material was selected because of its elevated maximum operation temperature in air and of its high thermal conductivity. A high maximum operation temperature was essential in order to avoid an active cooling system for the nozzle. Ceramic materials can work at very high temperatures and can be shaped into complex forms, but are generally weak in tension and lack ductility, hence they are very sensitive to failure due to thermal tensile stresses. A large thermal conductivity, allowing a more uniform temperature across the component, strongly reduces thermal stresses. As part of the design process, thermal stress analysis was performed on the structure. Results of that study have been used in the design and assembling of the burner. Thermal insulating gaskets inserted between the nozzle and the steel components are a simple and very efficient way to minimize thermal gradients in the structure. Thanks to a very low thermal conductivity, they assure a more uniform thermal profile in the ceramic nozzle, minimizing thermal stresses although producing an overall higher temperature. Cotronics ceramic paper $3000 \mathrm{~F}$, offering a thermal conductivity of $0.19 \mathrm{~W} / \mathrm{mK}$ and a thickness of $1 / 16^{\text {th }}$ of an inch, was selected for this set of experiments. Besides ensuring sealing between components, these soft gaskets are able to resist temperature up to

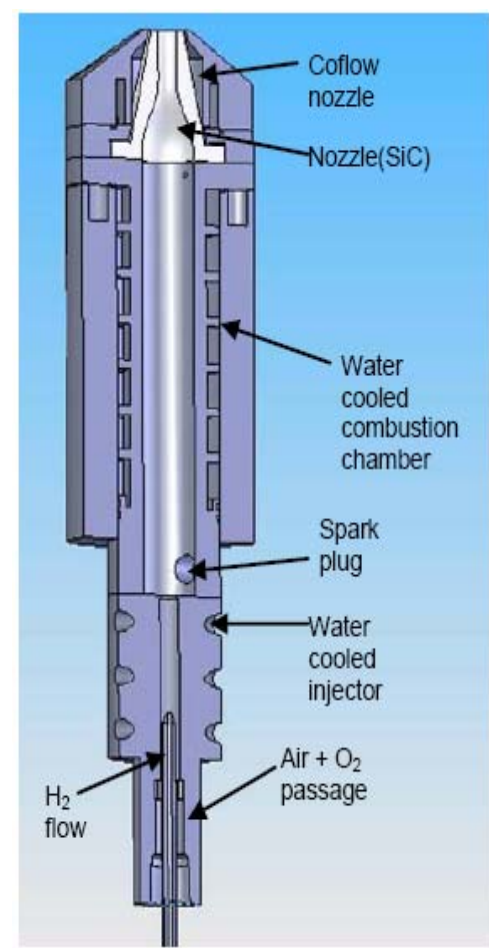

Figure 1: Schematic drawing of the laboratory scale burner

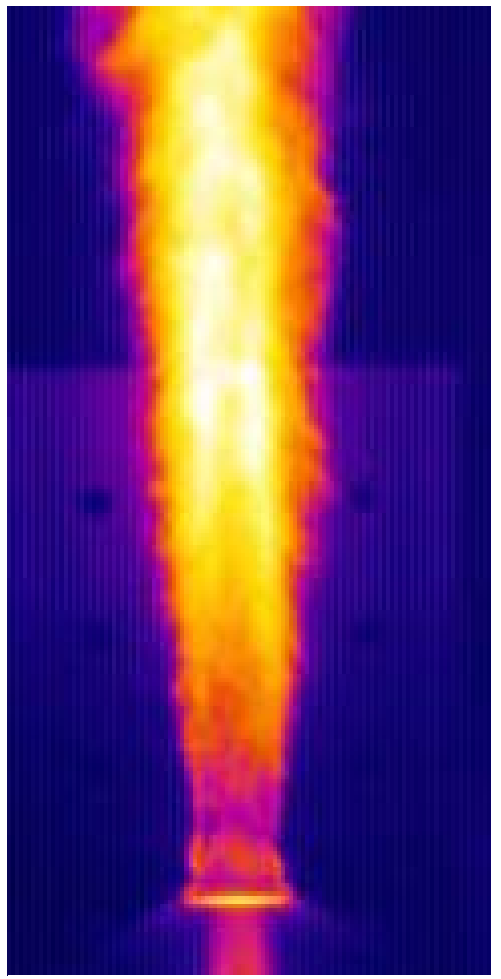

Figure 2. Infrared image of the free jet for $M_{e}=1.6, M_{f}=6$ and $H_{2}$ co-flow $1900 \mathrm{~K}$, and absorb thermal deformations of the steel without introducing additional stresses. 
Figure 2 is an infrared image of a typical flame obtained with the burner described above. The image is for a case with $M_{f}=6$ and $M_{e}=1.6$ and $\mathrm{H}_{2}$ co-flow. The flame originates at the interface between the fuel and the ambient air, and is attached to the edge of the co-flow nozzle.

The facility is very versatile and allows wide combinations of reactants. Hydrogen, methane and ethylene have been attempted as alternative fuels for the co-flow, whereas in some other experiments, the facility was operated with excess $\mathrm{H}_{2}$ and air or $\mathrm{H}_{2}$ was used in the co-flow. This variety of cases allows great flexibility to provide data targeted to specific CFD problems. For example, cases without combustion target turbulence models for mixing independent of the turbulence-chemistry interactions, whereas cases with robust flameholding and rapid reactions target the effects of heat release on the turbulence models.

The facility is also an excellent tool for development of new non-intrusive measurement techniques. It is not as costly as a hypersonic wind tunnel, offers excellent optical access and can be operated continuously for long periods. Laser measurements techniques can therefore be tested and improved in the laboratory environment. This work will focus on cases with vitiated air in the center jet and $\mathrm{H}_{2}$ in the co-flow. Other combinations will be the object of future studies.

\section{Experimental Setup}

Experiments were conducted to validate the numerical results. Four Hastings flowmeters with a nominal accuracy of $1 \%$ of full scale were used to control the mass flow rate of the incoming reactants. A 2500 SLPM flowmeter was used to regulate air, two 1000SLPM flowmeters were used for $\mathrm{H}_{2}$ (center jet and co-flow) and a 300 SLPM for $\mathrm{O}_{2}$. Flowmeters were calibrated for atmospheric pressure at the outlet. During a run the pressure at the exit of the flowmeters is much higher than atmospheric, and a set of experiments was performed to determine correction coefficients. The test showed that a higher exit pressure causes readings that are $1-2 \%$ too high for every 100 psi of exit pressure above atmospheric. Correction factors were determined for each flowmeter and mass flow rates adjusted accordingly. In addition, the flowmeters were originally calibrated for air, and corrections factors reported in the flowmeter manual, have been implemented to adjust for the different gases used. Table I reports the nominal volumetric flow rates for all the entries in our test matrix.

Pressure was measured in the burner, at the exit of the nozzle, and at the exit of the co-flow nozzle. Four type K thermocouples were used to monitor the temperature of the reactants, and the difference in the water temperature after passing through the cooling system. Unfortunately, measurements of the volumetric flow rate of the cooling water, and thus heat flux, are not available for this set of experiments because of a malfunctioning instrument.

A FLIR Thermacam was used to image the nozzle exit and measure the temperature. The emissivity of silicon carbide in the 3-5 $\mu \mathrm{m}$ range is about $0.8^{11}$. Neutral density filters were used to avoid camera saturation whenever necessary. We conducted a set of experiments in which a $\mathrm{SiC}$ sample was heated and temperature simultaneously measured with a thermocouple and with the camera. The tests verified the calibration of the camera, the filter transmittance and the material emissivity in the range of temperature of interest. Figure 3 shows a typical infrared image of the nozzle exit from which the surface temperature can be extracted. Two regions are easily distinguishable in the image: the nozzle "base" that is the external annular surface of the nozzle, separating the center jet from the co-flow, and the portion of the

Table I. Nominal volumetric flow rates in SLPM for the test matrix

\begin{tabular}{|l|c|c|c|l|c|}
\hline $\boldsymbol{M}_{\boldsymbol{e}}$ & $\boldsymbol{M}_{\boldsymbol{f}}$ & $\boldsymbol{Q}_{\mathrm{air}}$ & $\boldsymbol{Q}_{\mathrm{O} 2}$ & \multicolumn{1}{|c|}{$\boldsymbol{Q}_{\mathrm{H} 2}$} & $\boldsymbol{Q}_{\mathrm{H} 2 \text { co-flow }}$ \\
\hline $\mathbf{1 . 0}$ & $\mathbf{5 . 5}$ & 597.2 & 90.3 & 134.8 & 295.9 \\
\hline $\mathbf{1 . 0}$ & $\mathbf{6 . 0}$ & 533.5 & 101.3 & 151.3 & 274.8 \\
\hline $\mathbf{1 . 0}$ & $\mathbf{6 . 5}$ & 476.9 & 112.5 & 168.0 & 256.8 \\
\hline $\mathbf{1 . 0}$ & $\mathbf{7 . 0}$ & 426.1 & 123.9 & 185.1 & 241.3 \\
\hline $\mathbf{1 . 6}$ & $\mathbf{5 . 0}$ & 1195.2 & 141.5 & 211.3 & 572.4 \\
\hline $\mathbf{1 . 6}$ & $\mathbf{5 . 5}$ & 1058.7 & 160.0 & 239.0 & 524.6 \\
\hline $\mathbf{1 . 6}$ & $\mathbf{6 . 0}$ & 939.8 & 178.5 & 266.6 & 484.1 \\
\hline $\mathbf{1 . 6}$ & $\mathbf{6 . 5}$ & 835 & 197.0 & 294.3 & 449.6 \\
\hline $\mathbf{1 . 6}$ & $\mathbf{7 . 0}$ & 741.9 & 215.8 & 322.3 & 420.1 \\
\hline $\mathbf{2 . 0}$ & $\mathbf{6 . 0}$ & 1273.3 & 241.8 & 361.2 & 655.9 \\
\hline $\mathbf{2 . 0}$ & $\mathbf{6 . 5}$ & 1125.7 & 265.6 & 396.7 & 606.1 \\
\hline $\mathbf{2 . 0}$ & $\mathbf{7 . 0}$ & 995.3 & 289.5 & 432.3 & 563.6 \\
\hline
\end{tabular}

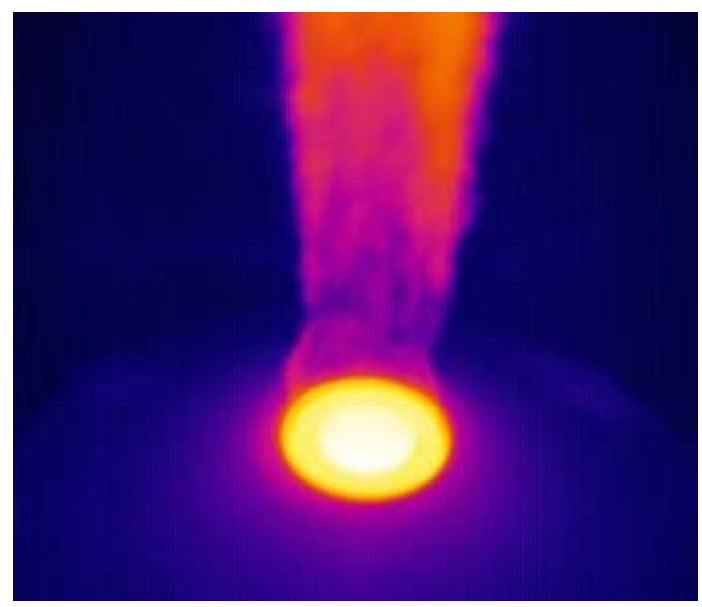

Figure 3. Infrared image of the nozzle exit for $M_{e}=1.6$ and $M_{f}=6$ internal walls of the nozzle visible to the camera. 


\section{Numerical Simulation}

\section{A. CFD-FEM approach}

Detailed numerical simulations of the internal flowfield were performed in order to determine whether the combustion would stabilize in the combustion chamber, whether the flow at the exit of the nozzle was uniform and shock wave free, and to verify that material temperature and thermal stresses did not exceed the limit of the materials. As a result, the flowfield at the exit of the nozzle is characterized for a wide range of conditions. These data can be used as boundary conditions for simulation of the external supersonic combusting coaxial jet or to validate measurements at the nozzle exit obtained with our CARS-IRS system and other non-intrusive techniques.

Accurate simulation of the internal flowfield requires knowledge of the wall temperature profile. In particular, the enthalpic content of the gas mixture at the exit of the jet is affected by the heat loss through the burner and the nozzle. Heat transfer from the nozzle to the co-flow determines the temperature of the fuel.

Two types of calculations were performed: calculations of the internal flow of the burner using the CFD code VULCAN, and finite element thermal and stress analysis using Cosmoworks, a commercial code. The two calculations were coupled. A tentative wall temperature profile was assigned to the burner and nozzle internal walls as boundary conditions for the CFD calculation. As a result, heat fluxes distribution and bulk temperature profiles were obtained. These data were given as boundary conditions for the finite element thermal analysis that returned an updated wall temperature profile. The process was then iterated until convergence on the wall temperature was achieved.

\section{B. Finite Elements Thermal Analysis}

The temperature distribution in the burner assembly was computed using Cosmoworks, a commercial finite element analysis code. Systematic calculations were performed for all the entries of the test matrix and were coupled to the CFD analysis.

Several heat transfer mechanisms compete in determining the temperature distribution in the structure. There is convection from the hot gas to the combustion chamber and nozzle, from the combustion chamber walls to the cooling water, and from the nozzle exterior walls to the $\mathrm{H}_{2}$ co-flow. There is conduction between the different components of the assembly, and there is radiation between the nozzle and the annulus wall, and to the ambient. The complexity of this thermal analysis goes far beyond the capabilities of the computational fluid dynamic code chosen. The finite element analysis software takes into account all the heat transfer mechanisms, except for radiation from the gas.

A temperature dependent model was generated for the Hexaloy grade SA silicon carbide based on the specifications provided by the manufacturer. Finite elements analysis of the Cotronics ceramic paper used as gasket would have required an excessively fine mesh; hence, we modeled only its insulating effect by introducing a "thermal resistance". In analogy with the electric field, the thermal resistance per unit of area is defined as $d / k$ where $d$ is the thickness of the gasket and $k$ is the thermal conductivity. Radiation from the solid surface to the ambient and to other surrounding surfaces is computed. The emissivity of stainless steel is assumed constant and equal to 0.7 , where a constant value of 0.92 is used for the ceramic. Temperature of the surrounding environment is assumed constant and equal to $300 \mathrm{~K}$. The radiative contribution from the hot gas is neglected. Water-cooled surfaces are assumed at a constant temperature of $390 \mathrm{~K}$, which is the approximate boiling temperature at the pressure of the water in the cooling passages. The heat convection is not modeled

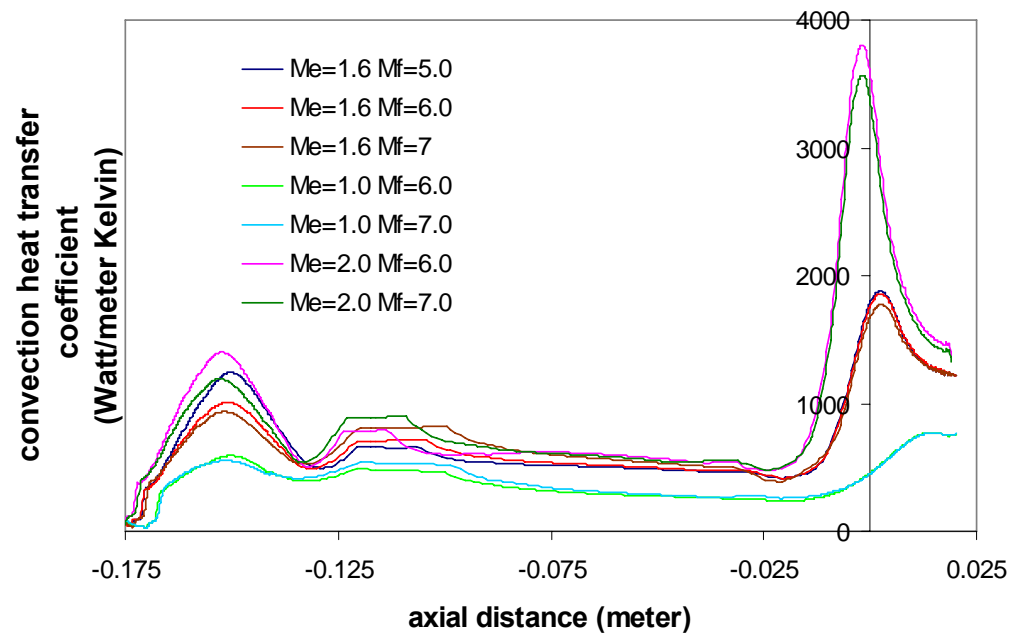

Figure 4. Convective heat transfer coefficient on the combustion chamber and nozzle internal wall for several values of flight and exit Mach number

directly by the software but a heat transfer coefficient and an adiabatic wall temperature, obtained from the CFD 
computations are required as input. Heat flux from the gas to the surface of the burner and the nozzle are obtained as output of the VULCAN code. Convection heat-transfer coefficient is computed as $h=q /\left(T_{a w}-T_{w}\right)$ where $q$ is the heat flux per unit area, $T_{a w}$ the adiabatic wall temperature, and $T_{w}$ is the wall temperature. The adiabatic wall temperature is approximated to the total temperature of the gas outside the thermal boundary layer. It is a function of the axial distance and is an output of the CFD code. For the wall temperature, the profile obtained as output of the thermal analysis in the previous iteration is used. For the first iteration, we assumed a tentative constant temperature for the burner and a larger, constant temperature for the nozzle. We chose the convection heat transfer coefficient over the heat flux as input for the FEM code because it decouples the fluid dynamics of the flow from the wall temperature. Figure 4 shows the computed convective heat transfer coefficient on the internal walls for several cases of interest. The coefficient depends strongly on the exit Mach number and only slightly on the enthalpic content of the gas. Heat transfer coefficient profiles are also evaluated for the surfaces cooled from the co-flow.

We took advantage of the axisymmetric nature of the problem, by limiting the analysis to a quarter of the structure. Only the combustion chamber, the nozzle and the co-flow-chamber are modeled. The analysis is further simplified by eliminating bolts, spark plugs and other small features that have a negligible effect on the temperature distribution. A non-structured grid of 87175 nodes defining 56426 tetrahedical elements is used for all of the calculations. The average element size is $3.0 \mathrm{~mm}$ but smaller elements are used to describe areas of greater interest or larger temperature gradients such as the nozzle, the contact surfaces between the ceramic and the metal, and the region where the co-flow impinges on the exterior wall of the nozzle. A grid made of 193092 nodes is used for grid convergence purposes. The temperature distribution obtained with this grid differs less than $1 \%$ from the one obtained with the original grid.

The temperature in the combustion chamber is almost uniform in the axial direction, but presents large thermal gradient in the radial direction. The sudden change in temperature between the nozzle and the burner is due to the insulating material. Thanks to the large thermal conductivity of the silicon carbide, the temperature in the radial direction appears to be uniform, although the interior is subject to a large heat flux from the accelerating gas, and the exterior is cooled by the $\mathrm{H}_{2}$ co-flow. A larger thermal

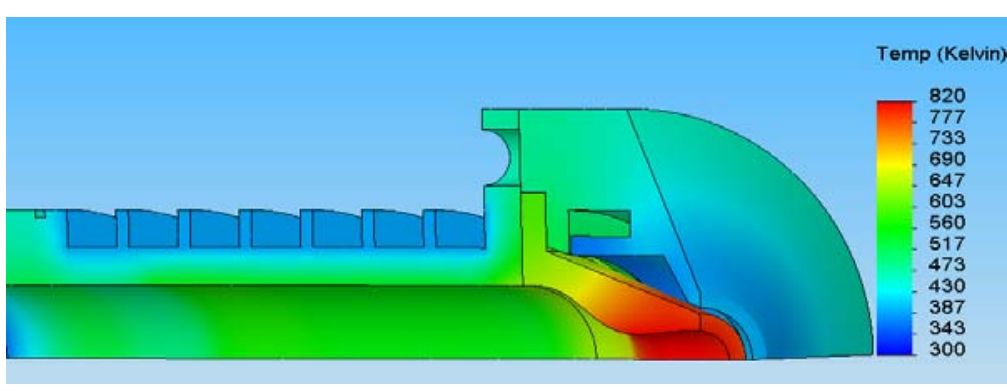

Figure 5. Temperature distribution in the burner for $M_{e}=1.6$ and $M_{\mathrm{f}}=6$ temperature difference can be seen in the axial direction, partially mitigated by the insulating gaskets. The "annulus" is heated by radiation from the nozzle and conduction from the combustion burner flange.

Updated wall temperature profiles are obtained as output of the thermal analysis and are given as input to the CFD code. The process is iterated until the peak difference between wall temperatures at the same location, as evaluated in two successive iterations, is below $1 \%$.

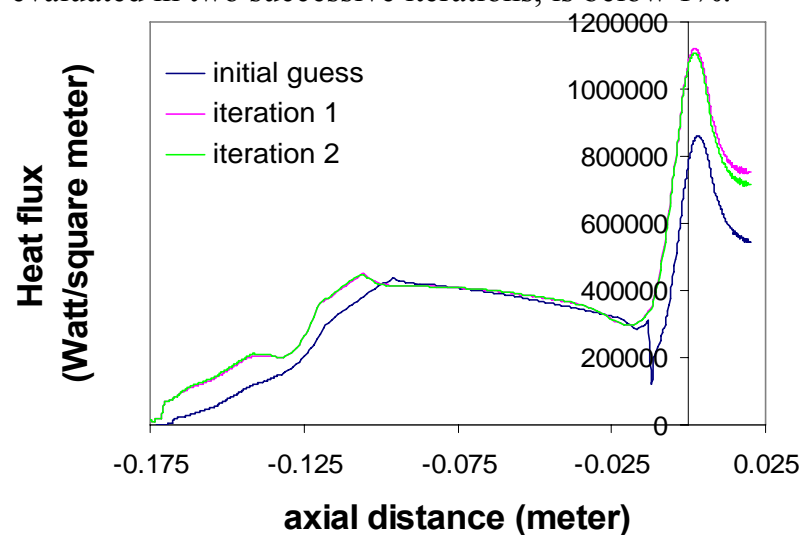

a)

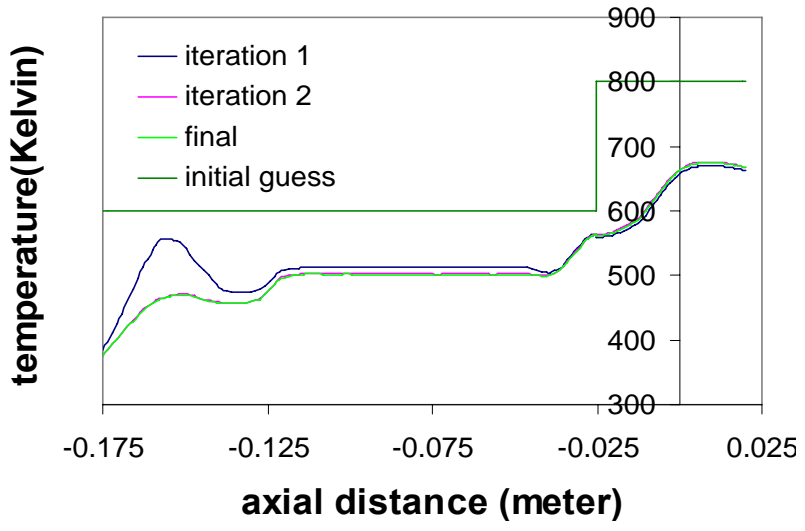

b)

Figure 6. Heat fluxes (a) and temperature distribution on the combustion chamber and nozzle internal walls

Figure $6 \mathrm{~b}$ shows that our initial guess for the temperature was too high but two iterations are sufficient to obtain a converged profile. Figure 7 a shows that the exit velocity appears to be unaffected by the wall temperature profile. 
Exit static temperature obtained with the initial guess for the wall temperature is instead quite different from the one achieved at the end of the iterative process. Temperature influences the combustion of the external jet; therefore, an accurate knowledge of the thermal profile at the nozzle exit will eventually lead to better results in the external jet simulation.
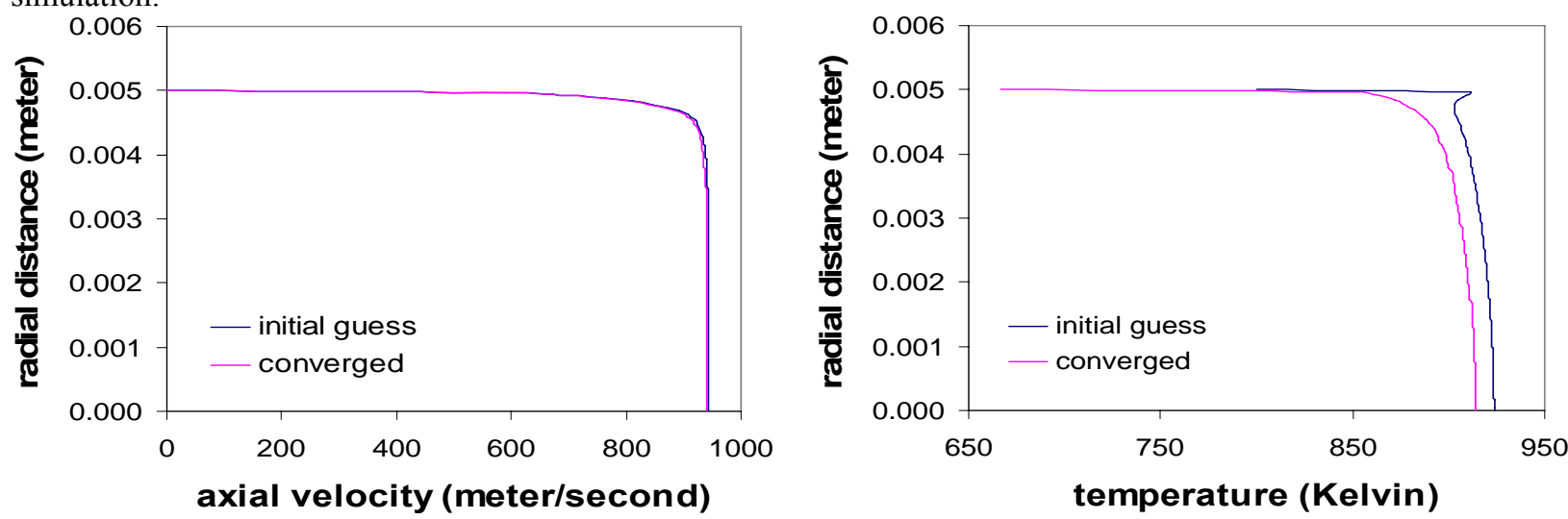

a)

b)

Figure 7. Axial velocity (a) and temperature profile (b) at the nozzle exit for the $M_{e}=1.6, M_{\mathrm{f}}=6$

\section{CFD Analysis}

All of the computational fluid dynamics results shown in this work were obtained using NASA Langley's VULCAN $^{12}$, a CFD code that solves the Favre averaged Navier Stokes equations using a finite volume method on a structured grid.

The flow is assumed axis-symmetric, and only a plane containing the axis is modeled. The structured grid, generated with a separate commercial code, has a total of 47225 points subdivided into air injection $(61 \times 29), \mathrm{H}_{2}$ injection $(49 \times 17)$, mixing chamber $(113 \times 45)$, combustion chamber $(313 \times 85)$ and nozzle $(145 \times 85)$. Grid points are clustered at the entrance of the combustion chamber, in the throat and expanding region of the nozzle. In the entire domain, the grid spacing near wall is such that $\mathrm{y}^{+}<50$ well within the domain of validity of wall matching functions $\left(y^{+}<100^{13}\right)$. The grid is further subdivided into 15 blocks to take advantage of the VULCAN block level parallelization.

A 2-interval, 7-coefficient curve fit created by McBride from NASA Lewis is used to model the mixture of thermally perfect gases. There are seven species $\left(\mathrm{O}_{2}, \mathrm{~N}_{2}, \mathrm{H}_{2}, \mathrm{H}_{2} \mathrm{O}, \mathrm{OH}, \mathrm{O}\right.$, and $\left.\mathrm{H}\right)$ and the Langley 7 -species 7 reaction model, included with the VULCAN distribution, was chosen to model the chemistry. Molecular viscosity is computed using the Sutherland's law, whereas Wassiljewa's law evaluates molecular conductivity. Inviscid fluxes are modeled using the Edwards low dissipation flux split scheme with second order, kappa $=1 / 3^{\text {rd }}$ MUSCL interpolation and a "smooth" limiter. The flow is assumed fully turbulent and the Wilcox k- $\omega$ turbulence model is used. The turbulent Prandtl number is set to 0.89, and the turbulent Schmidt number is set to 0.5.

Time integration is performed using a diagonalized approximate factorization scheme. Each domain is solved elliptically. A 3-level coarse to grid sequencing is implemented to accelerate convergence. The local CourantFriedrichs-Lewy (CFL) number is set to 4 for most of the calculations, and the time step is determined independently at each cell, based on its dimension and local flow properties.

A quasi 1D analysis provides the inflow conditions for all the entries in the test matrix in terms of mass flow rate of $\mathrm{H}_{2}, \mathrm{O}_{2}$ and air. The CFD software requires mass fractions, total temperature (set to $300 \mathrm{~K}$ ), velocity, static density, the turbulence intensity and the turbulent to molecular viscosity ratio. The product of the inflow velocity and static density is used to compute the mass flux and the mass flux is held constant. A supersonic outflow boundary with second order extrapolation of all variables is used for the simulation of the convergent-divergent nozzles. A subsonic outflow boundary condition with atmospheric backpressure is used for the sonic case. For all the walls, a temperature profile is assigned and the no slip condition imposed.

Two different stable solutions were obtained numerically simply by changing the initialization, as shown in Figure 8. In both cases the inflow conditions were propagated through the premixing chamber whereas the combustion chamber and the nozzle were filled with combustion products. Enforcing a quasi 1-D initialization with subsonic flow in the burner and a supersonic outflow sets the flame in the burner (top of figure) where assigning a constant, subsonic velocity throughout the burner and the nozzle produces a flame in the premixing chamber (bottom of figure). 


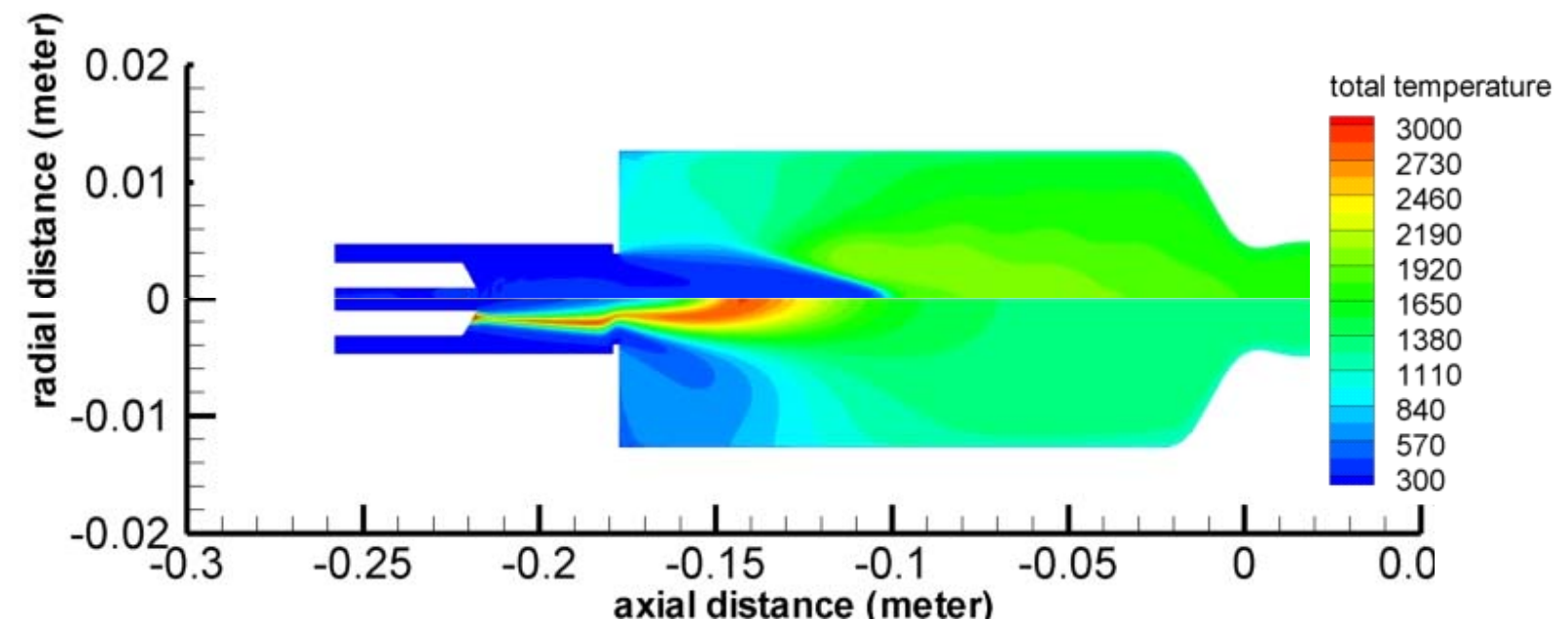

Figure 8: Total temperature distribution for the simulation with flameholding in the combustion chamber (top) and in the premixing chamber (bottom).

The two flames appear to be very different. The recirculation region generated by the sudden expansion ensures flameholding for the case displayed on the top portion of Figure 8. Figure 9 shows in more detail the injection region for the case with flame in the premixing chamber. The $\mathrm{OH}$ concentration (bottom of figure) reveals that the combustion occurs in the recirculation region generated at the tip of the $\mathrm{H}_{2}$ injection tube. If the combustion occurs in the burner the $\mathrm{O}_{2}$-enriched air and the $\mathrm{H}_{2}$ are well mixed prior to combustion, and combustion occurs only in lean mixtures. If the flame is at the tip of the $\mathrm{H}_{2}$ injection tube it contains a wider range of compositions, including compositions close to stoichiometric,

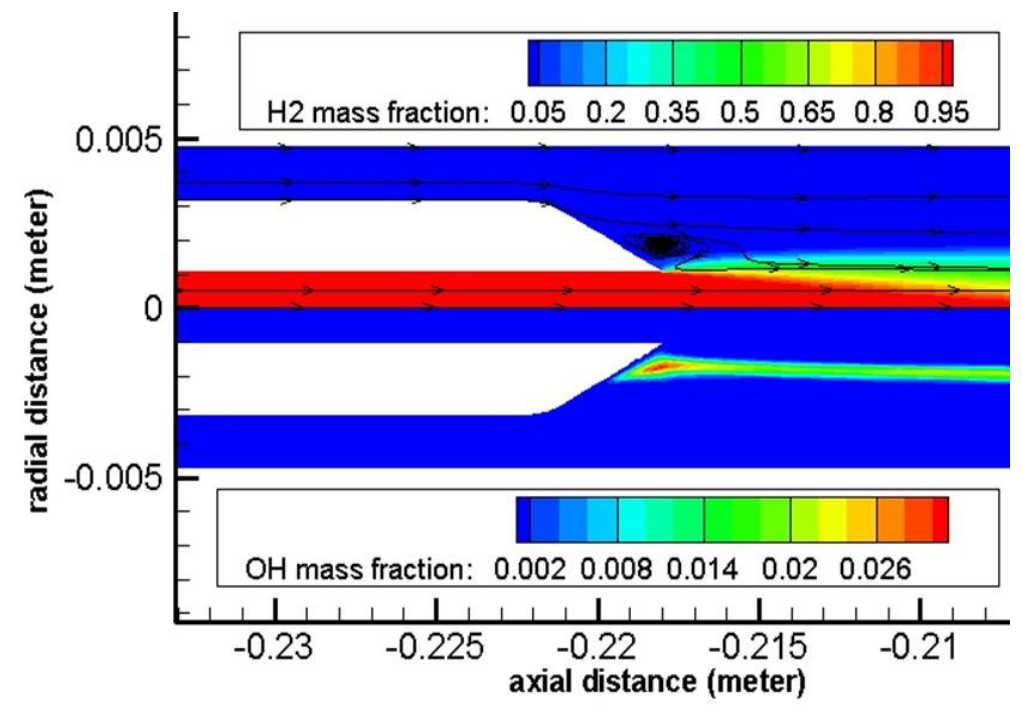

Figure 9. $\mathrm{H}_{2}$ (top) and $\mathrm{OH}\left(\right.$ bottom) at the end of the $\mathrm{H}_{2}$ injection tube and this explains the higher temperatures

displayed in the contour plot in the lower part of Figure 8. Since both solutions are plausible, an experiment was performed to evaluate where the flame was holding. A thermocouple was inserted right after the exit of the $\mathrm{H}_{2}$ tube, paying special attention to minimizing the perturbation to the flow. The measured temperature immediately increased above the limit of the thermocouple showing that a strong flame was present in this region. The flame is ignited by the spark plug at the entrance of the combustion chamber, and rapidly propagates upstream and holds at the $\mathrm{H}_{2}$ injection tube. The $\mathrm{H}_{2}$ injection tube is cooled internally by the $\mathrm{H}_{2}$ and externally by the enriched air, thus its temperature remains well below the maximum allowable. The premixing chamber surface is shielded from the hot gas by the cold enriched air jet and therefore the surface heat transfer is negligible.

Iterative convergence was considered achieved when the L2 norm of the residual of the governing equations was reduced by five orders of magnitude. Three grid levels are used for grid convergence verification. We generated a coarse grid by removing every other point from the "base" grid. A fine grid was generated by halving the grid spacing in both directions, but convergence was never achieved. We attempted a time accurate solution using a third order Runge-Kutta scheme, but no steady solution was obtained; strong periodic oscillations originated in the 
premixing chamber were found instead. This type of unsteady behavior was never observed during the tests conducted; therefore, this numerical solution was discarded. In this study, we are interested in describing accurately the flowfield at the nozzle exit and the heat fluxes on the combustion chamber and nozzle walls, not the ignition process. A "fine" grid was also generated by halving the grid spacing only in the combustion chamber and nozzle, keeping the same grid point distribution in the injector. Figure 10 shows the heat flux along the combustor and nozzle wall as evaluated on the three grid levels. The "base" solution is very different from the "coarse" but it is almost coincident with the "fine". The heat flux at the throat computed with the "base" grid is $2 \%$ lower than with the "fine" and $16.6 \%$ larger than with the "coarse" grid. At the nozzle exit, the difference is $5 \%$ and $16.7 \%$ with respect to the "fine" and the "coarse" respectively. Except for the throat and the exit, the heat flux profiles in the nozzle obtained with the "base" and "fine" grid match very well. Figure 11 provides velocity and temperature exit profiles obtained on the three grid levels. The profiles obtained with the "base" and "fine" grid are indistinguishable, with centerline values that differ by less than $0.1 \%$. We can conclude that for our variables of interest, grid convergence is satisfied with the "base" grid.

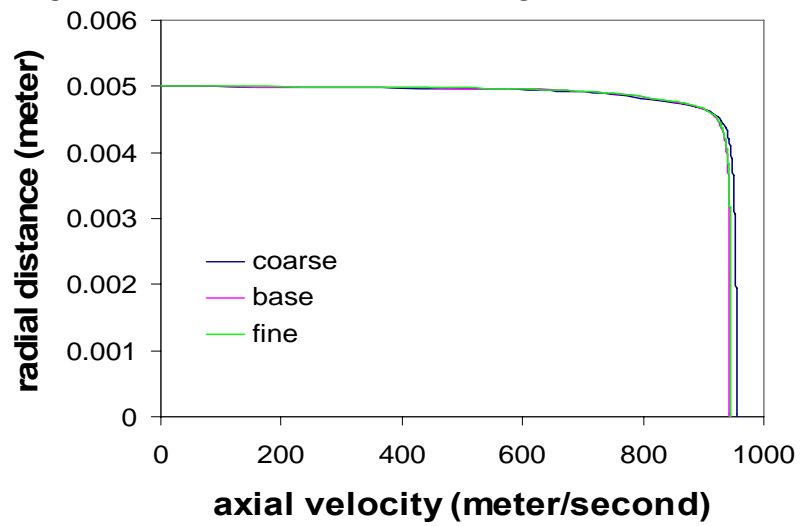

a)

Figure 11. Exit axial velocity a), and temperature b) on three grid levels

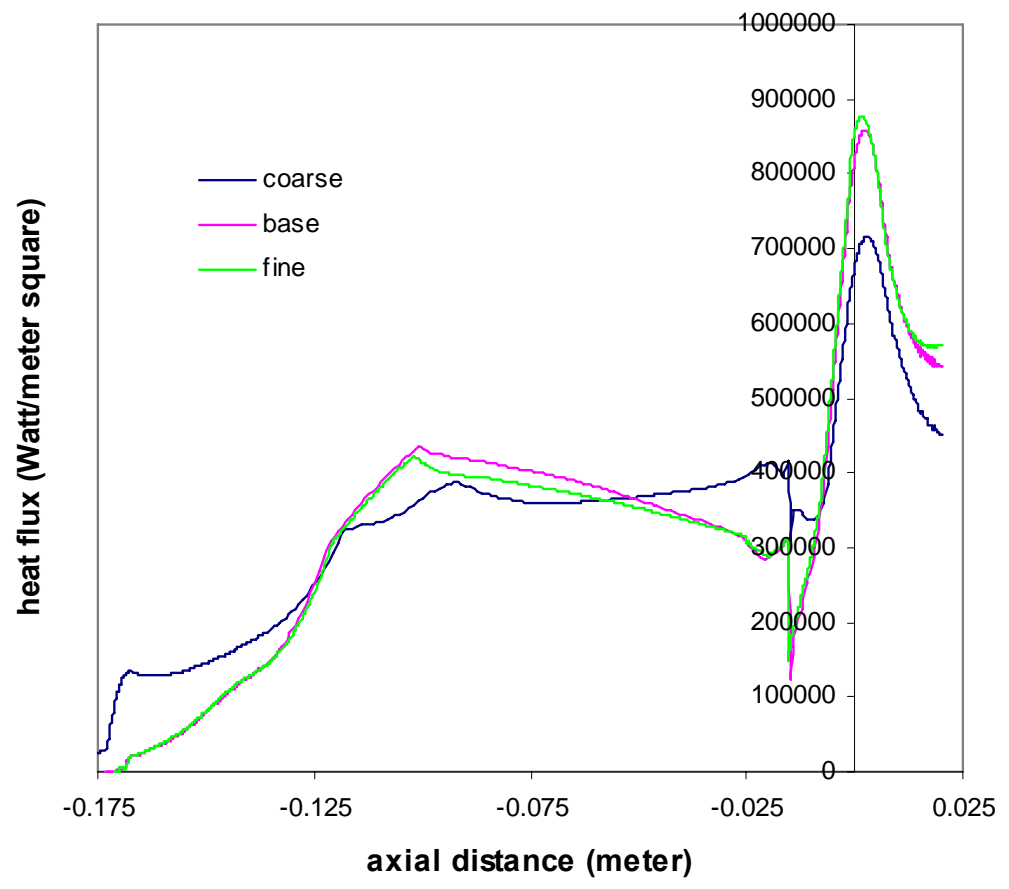

Figure 10. Heat fluxes on the combustion chamber and nozzle walls for the $M_{e}=1.6, M_{f}=5$ simulation obtained on three different grid levels

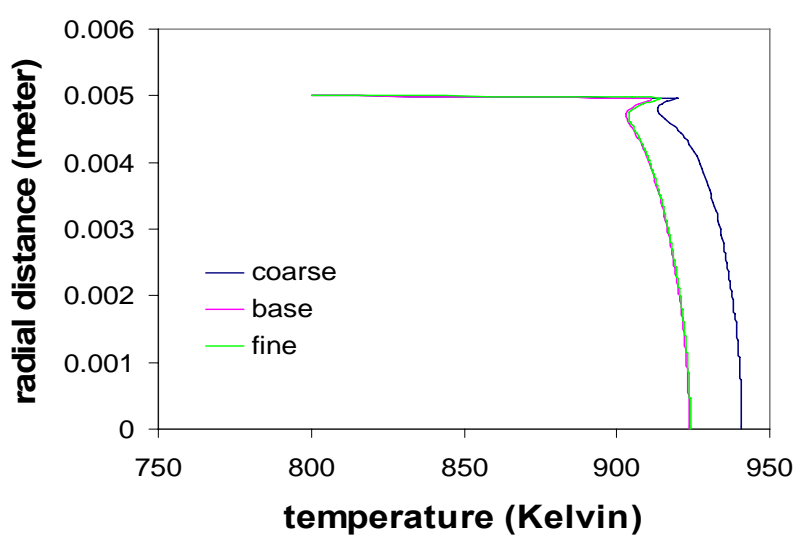

b) 


\section{Co-flow Simulation}

The VULCAN code was used also to determine the flowfield in the co-flow chamber. The purpose of this simulation is to determine heat fluxes on the exterior surface of the nozzle in order to obtain a more accurate temperature distribution. It also serves as an initialization for simulation of the free jet. As with the previous simulation, the flowfield is assumed axisymmetric and the flow fully turbulent. The modeling approach is the same as adopted previously, but no combustion is involved in this case. A structured grid consisting of 12186 points is used. Grid points are clustered near the wall so that $y^{+}<20$ everywhere, satisfying the criteria for using wall functions. A subsonic mass flow rate and total temperature are assigned at the inlet and atmospheric pressure assigned at the outlet. Temperature profiles are given on the walls and heat flux obtained as output. Flow is assumed turbulent everywhere, and the Wilcox $\mathrm{k}-\omega$ turbulence model is adopted.
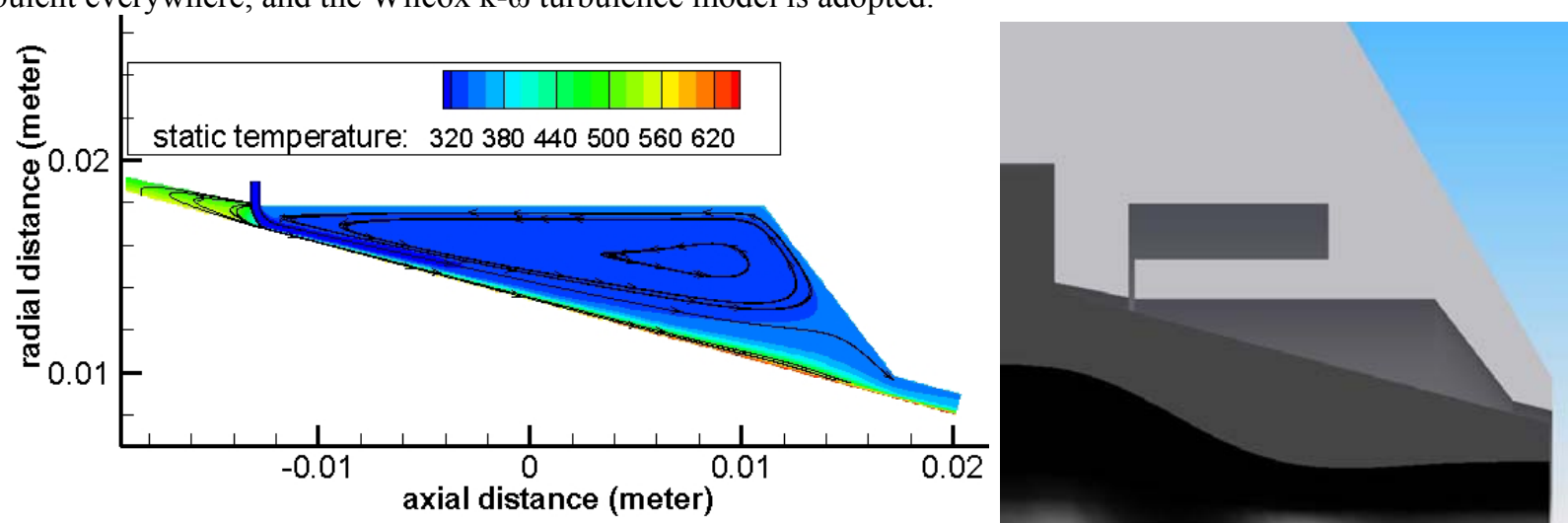

a)

b)

Figure 12. a) Streamlines and static temperature contour plot in the co-flow chamber for the $M_{e}=1.6$ and $M_{f}=6$ simulation $\left.b\right)$ Schematic drawing of the nozzle and co-flow nozzle

Figure 12 shows streamlines and a contour plot of static temperature distribution in the co-flow chamber. The plot clearly shows the increase in temperature of the $\mathrm{H}_{2}$ co-flow because of the heat transfer. The fuel temperature is an important parameter in a combustion simulation and figure clearly shows that the $\mathrm{H}_{2}$ temperature at the exit of the nozzle is affected by the nozzle wall temperature.

Figure 13 shows the computed heat fluxes on the exterior of the nozzle. $\mathrm{H}_{2}$ flow impinges directly on the nozzle surface producing very large heat fluxes, in a very small region. Thanks to the large thermal conductivity of silicon carbide, this does not generate a "cold" spot that would have caused high thermal stresses and possible material failure. Heat fluxes are obtained for all the cases of interest,

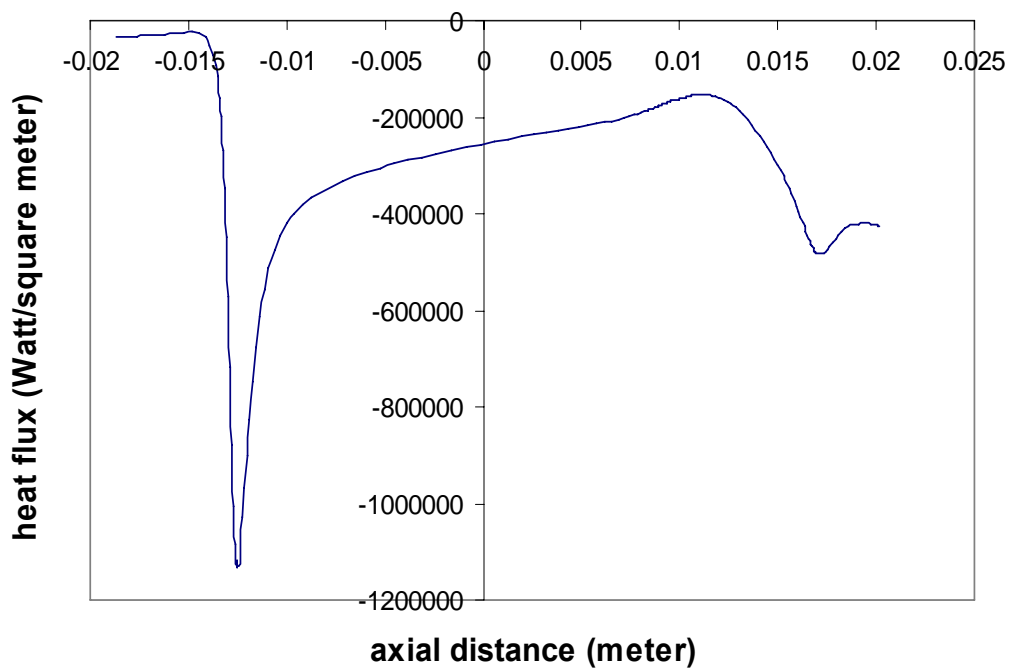

Figure 13. Heat flux on the nozzle external surface for $M_{e}=1.6$ and $M_{f}=5$. Axial distance is computed in a reference frame with origin at the nozzle throat. and are given as input to the finite element analysis.

\section{Results Analysis}

\section{A. Numerical Results}

A database of nozzle exit profiles was generated for several cases of interest providing boundary conditions for the simulation of the free coaxial jet, and a benchmark for validation of non-intrusive laser measurement techniques 
and other instrumentation. Figure 14a shows velocity exit profiles for different flight and exit Mach numbers; radial gradients are limited to the boundary layer. Centerline velocity increases with both exit Mach number, and with flight Mach number. Boundary layer thickness is about $0.4 \mathrm{~mm}$ for all the cases of interest. Figure 14b shows that temperature profiles are also uniform at the exit. The thermal boundary layer thickness decreases with the exit Mach number and increases with the simulated flight Mach number. Combustion products are fully mixed when they reach the nozzle exit and all species concentrations are constant along the radial direction.
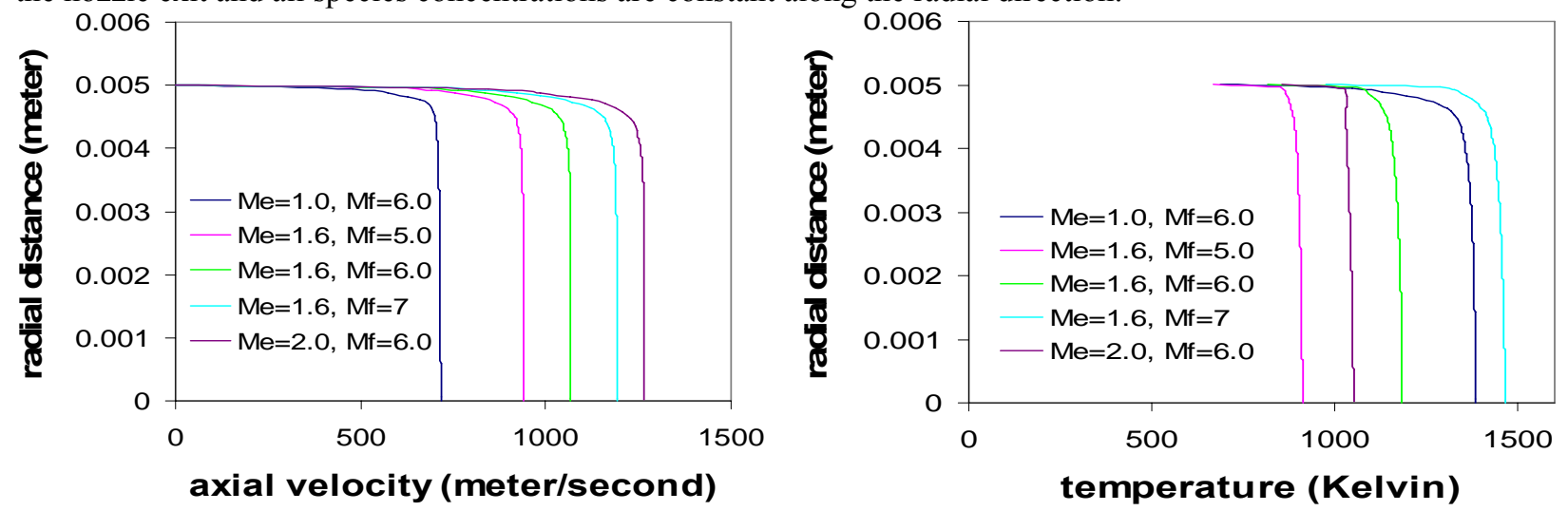

a)

b)

Figure 14. Axial velocity (a) and temperature (b) profiles at the nozzle exit for several values of flight and exit Mach number

Table II. Centerline values at the nozzle exit for several values of flight and exit Mach number

\begin{tabular}{|c|c|c|c|c|c|c|c|c|c|}
\hline $\boldsymbol{M}_{\boldsymbol{e}}$ & $\boldsymbol{M}_{\boldsymbol{f}}$ & $\boldsymbol{\rho}\left(\mathbf{k g} / \mathbf{m}^{\mathbf{3}}\right)$ & $\boldsymbol{U}(\mathbf{m} / \mathbf{s})$ & $\boldsymbol{M}$ & $\boldsymbol{T K E}\left(\mathbf{m}^{\mathbf{2}} / \mathbf{s}^{\mathbf{2}}\right)$ & $\boldsymbol{p}(\mathbf{a t m})$ & $\boldsymbol{T}(\mathbf{K})$ & $\mathbf{O}_{\mathbf{2}}$ & $\mathbf{N}_{\mathbf{2}}$ \\
\hline $\mathbf{1 . 0}$ & $\mathbf{5 . 5}$ & 0.268 & 677 & 0.965 & 5970 & 1.004 & 1230 & 0.231 & 0.650 \\
\hline $\mathbf{1 . 0}$ & $\mathbf{6 . 0}$ & 0.236 & 716 & 0.961 & 6712 & 1.004 & 1383 & 0.231 & 0.625 \\
\hline $\mathbf{1 . 0}$ & $\mathbf{6 . 5}$ & 0.209 & 753 & 0.956 & 7469 & 1.003 & 1534 & 0.231 & 0.598 \\
\hline $\mathbf{1 . 0}$ & $\mathbf{7 . 0}$ & 0.188 & 787 & 0.952 & 8236 & 1.003 & 1681 & 0.230 & 0.569 \\
\hline $\mathbf{1 . 6}$ & $\mathbf{5 . 0}$ & 0.381 & 939 & 1.548 & 1057 & 1.042 & 911 & 0.231 & 0.672 \\
\hline $\mathbf{1 . 6}$ & $\mathbf{5 . 5}$ & 0.326 & 1005 & 1.546 & 12114 & 1.035 & 1046 & 0.231 & 0.650 \\
\hline $\mathbf{1 . 6}$ & $\mathbf{6 . 0}$ & 0.283 & 1068 & 1.542 & 13708 & 1.030 & 1183 & 0.231 & 0.625 \\
\hline $\mathbf{1 . 6}$ & $\mathbf{6 . 5}$ & 0.262 & 1133 & 1.541 & 15456 & 1.026 & 1327 & 0.231 & 0.598 \\
\hline $\mathbf{1 . 6}$ & $\mathbf{7 . 0}$ & 0.221 & 1189 & 1.538 & 17070 & 1.022 & 1458 & 0.231 & 0.569 \\
\hline $\mathbf{2 . 0}$ & $\mathbf{6 . 0}$ & 0.345 & 1263 & 1.929 & 18816 & 1.063 & 1050 & 0.231 & 0.625 \\
\hline $\mathbf{2 . 0}$ & $\mathbf{6 . 5}$ & 0.285 & 1337 & 1.924 & 21068 & 1.049 & 1178 & 0.231 & 0.598 \\
\hline $\mathbf{2 . 0}$ & $\mathbf{7 . 0}$ & 0.252 & 1409 & 1.919 & 23422 & 1.043 & 1307 & 0.231 & 0.569 \\
\hline
\end{tabular}

Table II summarizes the numerical results taken at the exit, on the centerline, for several parameters of interest, providing the user of the facility with a powerful tool to validate their instruments. Since the flow is uniform outside of the boundary layer, the values reported in the table are valid in a large area at the nozzle exit, therefore small uncertainties on the measurement position, or averaging process in a measurement volume, will not affect the validation process. For all the cases in Table II the exit pressure is slightly above atmospheric, therefore, the jet is under-expanded: expansion waves will depart from the nozzle exit, and a system of expansion and compression waves will be generated. In addition, the co-flow will interact with the center-jet further altering it. Hence, measurements for an instrument validation study need to be made as close as possible to the nozzle exit, typically less than a radius away from the nozzle.

\section{B. Numerical versus experimental results}

Table III compares measurements of static pressure at the end of the combustion chamber to computational results. Pressure measurements for the $M_{e}=1$ nozzle present a very low value of the total pressure for $M_{f}=5.5,6$ and 6.5 and excellent agreement for $M_{f}=7$. Water temperature measurements and IR images suggest that combustion is not complete with the $M_{e}=1$ nozzle for flight Mach number below 7. The $M_{e}=1.6$ simulations offer an excellent 
agreement with the measured values for all the flight Mach numbers. Run to run variation of the pressure readings has a standard deviation of $0.04 \mathrm{~atm}$, equal to or larger than the difference between the measured and computed pressure.

Results are not satisfactory for the $M_{e}=2$ cases, the error is systematic and too large to be attributed to the instruments. We measured the nozzle throat for the three nozzles by using calibrated pin gauges. For the sonic and $M_{e}=1.6$ nozzle the throat matches the value given as design with an uncertainty of 0.001 inches whereas for the $M_{e}=2$ nozzle the measured throat radius is between 1.9 and $2.2 \%$ larger than the design value used for the CFD model. The nozzle throat area for the $M_{e}=2$ nozzle is therefore between $3.8 \%$ and $4.4 \%$ larger than the design, explaining the lower values of pressure measured. Since the nozzle area ratio is different from design, also the centerline values, reported in Table II, would not match the experimental results.

Table IV compares the measured average temperature on the nozzle "base" with the computed one for the case with $\mathrm{M}_{\mathrm{e}}=1.6$. The

Table III. Computed and measured static pressure in the burner for several values of flight and exit Mach number

\begin{tabular}{|c|c|c|c|c|c|}
\hline$M_{e}$ & $M_{f}$ & CFD(atm) & Measured(atm) & $\Delta$ (atm) & $\Delta(\%)$ \\
\hline 1.0 & 5.5 & 1.789 & 1.18 & -0.61 & -34.24 \\
\hline 1.0 & 6.0 & 1.774 & 1.17 & -0.60 & -34.05 \\
\hline 1.0 & 6.5 & 1.759 & 1.13 & -0.62 & -35.51 \\
\hline 1.0 & 7.0 & 1.745 & 1.75 & 0.00 & 0.12 \\
\hline 1.6 & 5.0 & 4.144 & 4.16 & 0.02 & 0.48 \\
\hline 1.6 & 5.5 & 4.082 & 4.08 & -0.01 & -0.16 \\
\hline 1.6 & 6.0 & 4.015 & 4.06 & 0.04 & 1.08 \\
\hline 1.6 & 6.5 & 3.965 & 3.98 & 0.02 & 0.44 \\
\hline 1.6 & 7.0 & 3.915 & 3.93 & 0.01 & 0.29 \\
\hline 2.0 & 6.0 & 7.809 & 7.36 & -0.45 & -5.72 \\
\hline 2.0 & 6.5 & 7.640 & 7.19 & -0.45 & -5.89 \\
\hline 2.0 & 7.0 & 7.507 & 7.01 & -0.50 & -6.64 \\
\hline
\end{tabular}

difference in the numerical and experimental results is large and further analysis was required to explain this discrepancy.

A sensitivity study was conducted to evaluate the effect of some uncertainties in the input for the thermal analysis. Major sources of concern were the thermal insulating gaskets. The thermal conductivity value provided by the manufacturing company is for the material in its natural state and not when compressed, as in our assembly. A numerical simulation was performed, setting the thermal resistance to zero; although the thermal gradients in the axial direction were increased, the base temperature was lowered only by $3 \%$. Similar results have been obtained by reducing the cooling water temperature to $300 \mathrm{~K}$

Table IV. Measured and computed nozzle base temperature for $M_{e}=1.6$

\begin{tabular}{|l|c|c|l|}
\hline $\boldsymbol{M}_{\boldsymbol{f}}$ & Measured (K) & Numerical (K) & $\boldsymbol{\Delta} \%$ \\
\hline $\mathbf{5 . 0}$ & 566 & 655 & 15.72 \\
\hline $\mathbf{5 . 5}$ & 611 & 723 & 18.33 \\
\hline $\mathbf{6 . 0}$ & 654 & 791 & 20.95 \\
\hline $\mathbf{6 . 5}$ & 685 & 862 & 25.84 \\
\hline $\mathbf{7 . 0}$ & 726 & 932 & 28.37 \\
\hline
\end{tabular}
(nozzle "base" temperature reduction less than 1\%), or by including radiation from the interior of the nozzle to the combustor walls (nozzle "base" temperature reduction 1.6\%). None of these sources of error, even if combined could explain the large difference between the experimental and numerical values.

In the CFD model, we assumed the flow fully turbulent. Numerous studies ${ }^{14,15,16,17}$ have shown that a turbulent boundary layer, subject to strong acceleration, can undergo a reverse transition and revert to a laminar-like behavior near the wall. This results in a strongly reduced heat transfer and a departure from the behavior of a fully turbulent boundary layer. Cooling of the nozzle also favors the boundary layer relaminarization. A true laminar boundary layer can be achieved only asymptotically. When the driving force (pressure gradient and cooling for our nozzle) is removed, then the boundary layer will transition back to fully turbulent. Several criteria are available to determine the onset of the "relaminarization". Launder introduced an acceleration parameter $K_{1}=\frac{v}{U^{2}} \frac{d U}{d x}$ and suggested that relaminarization would occur for values greater than 3.3-3.5 $10^{-6}$. Narashima suggested that the relaminarization threshold should go down when the Reynolds number based on momentum thickness $\operatorname{Re}_{\theta}$ increases. Haney defined a different acceleration parameter $K_{4}=\frac{\frac{v_{e}}{U_{e}^{2}} \cdot \frac{d U_{e}}{d x}}{4.507 \cdot 10^{-3} \operatorname{Re}_{\theta}^{-1.25}}$ where $\operatorname{Re}_{\theta}=\frac{\rho_{e} U_{e} \theta}{\mu_{w}}$ and $\theta$ is the momentum thickness. Notice that the dynamic viscosity is evaluated at the wall rather than outside the boundary layer to take into account compressibility effects. Relaminarization would occur for $K_{4}>1$. The criterion is immediately satisfied at the nozzle entrance, but not in the divergent section of the supersonic nozzles. For the sonic nozzle, the acceleration factor stays greater than 1 up to the exit. Neither of these criteria takes into account the stabilizing effect of the cooling, 
hence they underestimate the length of the "quasi-laminar" region. On the other hand, the nozzle surface is rough, with tooling marks, and this is likely to trigger re-transition to turbulence.

An additional CFD simulation has been run for the case with $M_{f}=5$ and $M_{e}=1.6$ assuming the boundary layer laminar in the convergent region of the nozzle, where $K_{4}>1$, and turbulent in the divergent, where $K_{4}<1$. The flow outside the boundary layer is assumed turbulent through the entire nozzle. Figure 15 compares the outflow profiles obtained with and without relaminarization in the convergent section of the nozzle.
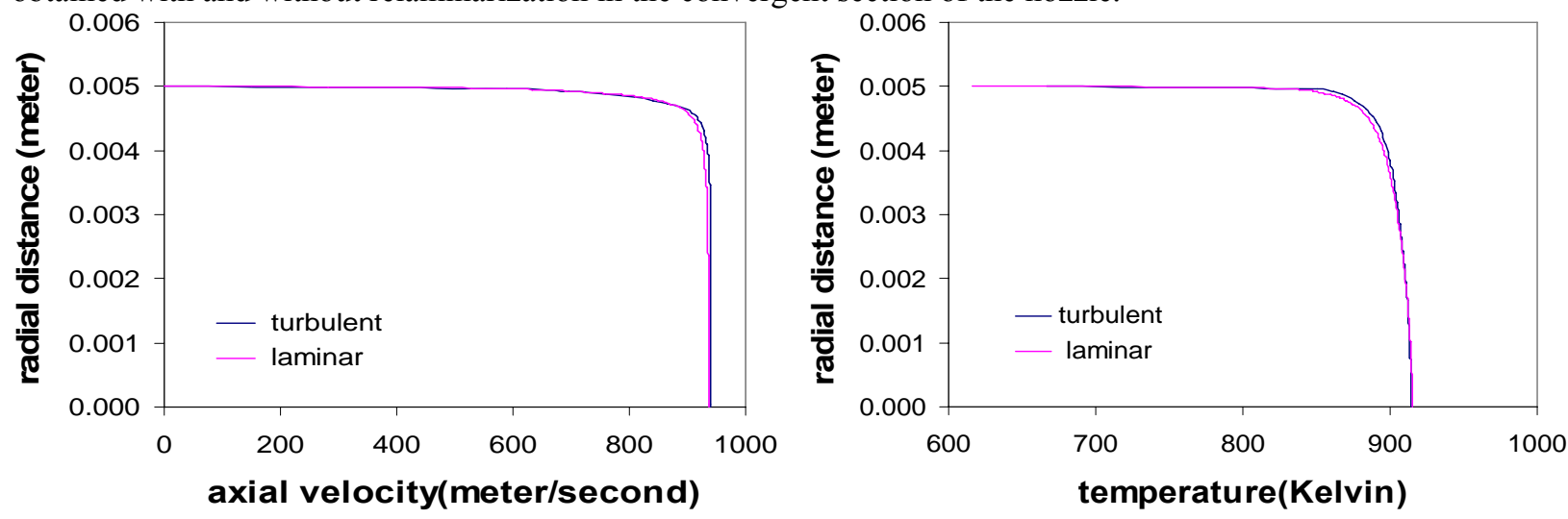

a)

b)

Figure 15. Velocity (a) and static temperature (b) at the nozzle exit for $M_{e}=1.6$ and $M_{f}=5$ assuming a turbulent (blue) or a laminar (pink) boundary layer in the convergent part of the nozzle

Velocity and temperature profiles at the exit are almost unaffected by the relaminarization. In particular, the centerline values, listed in Table II, are still valid, except for the turbulent kinetic energy as shown in Figure 16. The new nozzle base temperature is $601 \mathrm{~K}$, still $46 \mathrm{~K}$ $(8 \%)$ larger than the one measured. This result was expected because the criterion chosen neglects the effects of the cooling on the wall. If the boundary layer is assumed laminar throughout the nozzle the base temperature is $476 \mathrm{~K}$, about $15 \%$ lower than measured. This result suggests that the boundary layer re-transitions to turbulence along the divergent section of the nozzle. Pin-pointing where the retransition occurs would be difficult and would add very little to the results obtained. The code does not model either

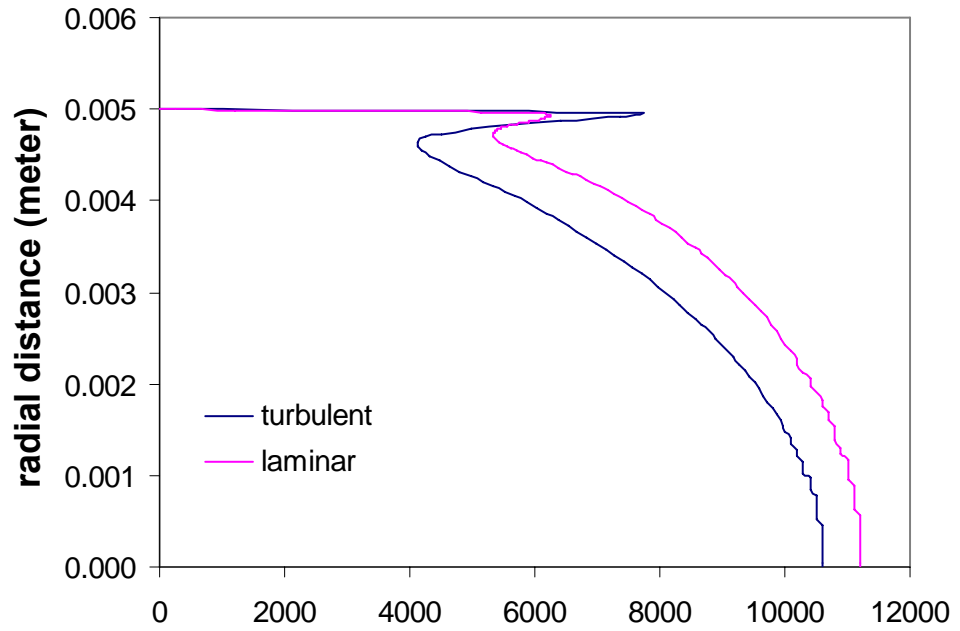

turbulent kinetic energy (meter square/second square)

Figure 16. Turbulent kinetic energy at the nozzle exit

transition or the "quasi laminar" state of the boundary layer, but simply suppresses turbulence in the boundary layer. This approach works well for the heat transfer since, in terms of heat transfer, a "quasi laminar" state is very well approximated by a true laminar boundary layer, and the transition region is small enough to contribute very little to the total heat fluxes. This, combined with the large thermal conductivity of the ceramic, allows good results to be obtained with this approach for heat transfer and temperature distribution, but not necessarily for other variables at the nozzle exit, in particular turbulent kinetic energy and eddy viscosity ratio. Our approach does not model the very complex physics of the relaminarization and it served mainly to validate our explanation of the difference between the numerical and experimental results.

\section{Conclusion}

A laboratory scale burner, providing a sonic or supersonic center jet and a $\mathrm{H}_{2}$ or hydrocarbon co-flow, was developed for CFD validation studies and to test new or improved laser measurements techniques. The flowfield 
inside the burner was computed for a wide range of operative conditions. CFD simulations were coupled to FEM thermal analysis to obtain results that are more accurate. A large database of outflow and wall temperature profiles was generated for a wide range of conditions of interest providing accurate boundary conditions for the analysis of the external combusting coaxial jet, and a benchmark to validate new or improved non-intrusive measurement techniques. Experiments have been essential in correctly interpreting the numerical results revealing that the flow was more complex than expected (relaminarization, and retransition to turbulence). Numerical simulations employing a laminar boundary layer through the convergent section or the whole nozzle substantiated this conclusion.

Future numerical simulations will focus on the external jet using the database obtained from this study as boundary conditions. A sensitivity study to the Schmidt and Prandtl numbers, and to different profiles of turbulent kinetic energy, will be the object of these simulations. Future experiments will involve measurements of velocity, temperature, and composition with an improved version of our CARS-IRS system and results will be compared to numerical simulations.

\section{Acknowledgments}

This effort was conducted at NASA Langley Research Center in the laboratories of the Hypersonic Airbreathing Propulsion Branch. Sponsorship was by the Defense Test Resource Management Center's (DTRMC) Test and Evaluation/Science and Technology (T\&E/S\&T) program, under the Hypersonic Test focus area, and by NASA's Fundamental Aeronautics Hypersonics Program. The authors would like to thank L.G. Wilson for technical support in performing these experiments, and R. Baurle and R. Gaffney for support with the Vulcan code.

\section{References}

\footnotetext{
${ }^{1}$ Hancock, R. D., Schauer, F. R., Lucht, R. P., Farrow, R. L., "Dual-pump CARS measurements of nitrogen and oxygen in a laminar jet diffusion flame," Appl. Opt. 36, pp. 3217-3226, 1997.

${ }^{2}$ O'Byrne, S., Danehy, P. M., Cutler, A. D., "Dual Pump CARS Thermometry and Species Concentration Measurements in a Supersonic Combustor," AIAA Paper 2004-0710, 42 ${ }^{\text {nd }}$ AIAA Aerospace Sciences Meeting, Reno, NV, Jan 5-8, 2005

${ }^{3}$ Tedder, S. A., O’Byrne, S., Danehy, P. M., Cutler, A. D. , "CARS Temperature and Species concentration Measurements in a Supersonic Combustor with Normal Injection," AIAA Paper 2005-0616, 43 ${ }^{\text {rd }}$ AIAA Aerospace Sciences Meeting, Reno, NV, Jan 5-8, 2005

${ }^{4}$ Bivolaru, D., Danehy, P. M., Lee, J. W., Gaffney, R. L., Cutler, A. D., "Single Pulse, Multi-point Multi-component Interferometric Rayleigh Scattering Velocimeter," AIAA-2006-836, 44 ${ }^{\text {th }}$ AIAA Aerospace Sciences Meeting Reno, NV, 9-12 Jan 2006

${ }^{5}$ Bivolaru, D., Danehy, P. M., Grinstead, K. D., Tedder, S. A., Cutler, A. D., "Simultaneous CARS and Interferometric Rayleigh Scattering,” AIAA-2006-2968, AIAA AMT-GT Technology Conference, San Francisco, June 2006.

${ }^{6}$ Rodriguez, C. G., Cutler, A. D., "Computational Simulation of a Supersonic-Combustion Benchmark Experiment," $41^{\text {st }}$ AIAA/ASME/SAE/ASEE Joint Propulsion Conference and Exhibit, Tucson, Arizona, July 10-13, 2005

${ }^{7}$ Cutler, A. D., Magnotti, G., Baurle, R., Bivolaru, D., Tedder, S. A., Danehy, P. M., Weikl, M., Beyrau, F., Seeger, T. "Development of Supersonic Combustion Experiments for CFD Model development,"AIAA 2008-0978, 45" AIAA Aerospace Sciences Meeting Reno, NV, Jan 2007

${ }^{8}$ Tedder, S. A., Bivolaru, D., Danehy, P. M., Weikl, M. C., Beyrau, F., Seeger, T., Cutler, A. D, "Characterization of a Combined CARS and Interferometric Rayleigh Scattering System and Demonstration in a Mach 1.6 Combustion-Heated Jet", AIAA-2007-0871, 45 ${ }^{\text {th }}$ AIAA Aerospace Sciences Meeting and Exhibit, Reno, NV, Jan. 8-11, 2007.

${ }^{9}$ Cutler, A. D., Magnotti, G., Capriotti, D. P., Mills, C. T., "Supersonic Combusting Jet Experiments for Code Development and Validation," Paper 1150, 55 JA JANAF Propulsion Meeting, Boston, MA, May 12-18, 2008.

${ }^{10}$ Danehy, P. M., Magnotti, G., Bivolaru, D., Tedder, S. A., Cutler, A. D., "Simultaneous Temperature and Velocity Measurements in a Large-Scale, Supersonic, Heated Jet," Paper 1193, 55 ${ }^{\text {th }}$ JANNAF Propulsion Meeting, Boston, MA, May 12$18,2008$.

${ }^{11}$ Postlethwait, M. A., Sikka, K. K., Modest, M. F., Hellmann, J. R., "High Temperature normal spectral emittance of Silicon Carbide based materials," Journal of Thermophysics and Heat Transfer, Vol. 8, No. 3, 1994

${ }^{12}$ Baurle, R. A., www.vulcan.cfd.larc.nasa.gov/WebPage Manual/vulcan manual.html, [cited 8 June 2008]

${ }^{13}$ Wilcox, D. C., Turbulence Modeling for CFD, DCW Industries Inc., $2^{\text {nd }}$ ed., 1998

${ }^{14}$ White, F. M. Viscous Fluid Flow, McGraw-Hill, $2^{\text {nd }}$ ed., New York, 1991

${ }^{15}$ Narasimha, R., Sreenivasan, K. R., “ Relaminarization in highly accelerated turbulent boundary layers,” Journal of Fluid Mechanics, Vol 61, part 3, 1973

${ }^{16}$ Launder, B. E., "Laminarization of the turbulent boundary layer by acceleration”, Report no 77, Gas Turbine Lab, M.I.T. 1964

${ }^{17}$ Jentink, T. N., "An evaluation of nozzle relaminarization using low Reynolds number k- $\varepsilon$ turbulence model", AIAA 930610, $31^{\text {st }}$ AIAA Aerospace Sciences Meeting Reno, NV, 11-14 Jan 1993
} 